\title{
金属镍基质上直立六边形 $\mathrm{NiO}$ 纳米片的 制备与光催化性能
}

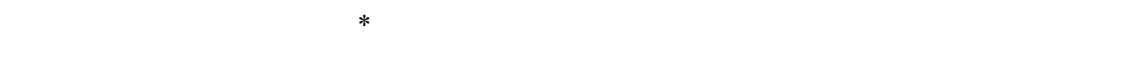

李 丽 $^{\circledR}$ 马军虎 ${ }^{\circledR}$ 王明珍 ${ }^{\circledR}$

(1) 陕西师范大学化学与材料科学学院, 大分子科学陕西省重点实验室, 西安 710062; (2) 陕西省咸阳师范学院化学系, 咸阳 712000 .

*联系人, E-mail: hqyang@,snnu.edu.cn)

摘要 通过金属镍片与草酸钠的碱性溶液于 $140^{\circ} \mathrm{C}$ 水热反应 $24 \mathrm{~h}$ ，在金属锦片表面原位生长出大面积直 立的六边形 $\mathrm{Ni}(\mathrm{OH})_{2}$ 纳米片, 经 $600^{\circ} \mathrm{C}$ 退火 $2 \mathrm{~h}$ 后得到六边形 $\mathrm{NiO}$ 纳米片. 采用 $\mathrm{X}$ 射线衍射仪、扫描电子显 微镜和透射电子显微镜对产物进行了表征. 结果表明, 六边形 $\mathrm{Ni}(\mathrm{OH})_{2}$ 纳米片为六方相单晶结构, 厚度 大约在 200 500 nm范围, 对角线的长度大约在 1.6 3.6 $\mu \mathrm{m}$ 范围, 六边形 $\mathrm{NiO}$ 纳米片为立方相单晶结构. 研究了草酸钠在六边形 $\mathrm{Ni}(\mathrm{OH})_{2}$ 纳米片形成过程中的作用以及六边形 $\mathrm{NiO}$ 纳米片的光催化特性, 提出了 可能的生长机理, 发现六边形 $\mathrm{NiO}$ 纳米片对空气和双氧水氧化甲基橙具有一定的光催化作用.

关键词 $\mathrm{Ni}(\mathrm{OH})_{2} \mathrm{NiO}$ 六边形纳米片 水热法

$\mathrm{NiO}$ 是非常重要的 $\mathrm{p}$ 型半导体, 由于其独特的电 学、磁学和催化特性广泛用作电池的电极, 催化剂, 电致变色薄膜, $\mathrm{H}_{2}, \mathrm{NO}_{2}, \mathrm{NH}_{3}$ 等气体传感和磁性材料 [1 3], 这些材料的性能在很大程度上决定于 $\mathrm{NiO}$ 的尺 寸和形貌, 同时这些纳米材料也是构筑纳米器件的 基本模块. 所以各种新颖形貌纳米结构的制备具有 非常重要的科学意义. 目前, 人们采用高温有机溶剂 回流法、水热法、溶胶一凝胶法、多孔氧化铝模板与 电化学法等制备出了由纳米颗粒组装的三维超晶格 结构 ${ }^{[4]} 、 \mathrm{NiO}$ 的纳米颗粒 ${ }^{[5 \sim 7]}$ 和有序微孔结构 ${ }^{[8]}$ 、纳 米线 $[9,10]$ 、纳米管 ${ }^{[11]}$ 、纳米棒 ${ }^{[12]}$ 、纳米带 $[13,14]$ 、纳

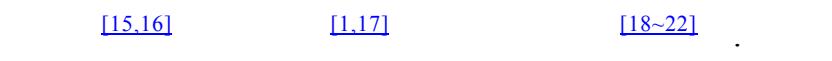
$\mathrm{NiO}$ 纳米片的制备, Liang等人 ${ }^{[1]}$ 首次利用醋酸镍与氨 水于 $200{ }^{\circ} \mathrm{C}$ 水热反应, 得到厚度大约 $200 \mathrm{~nm}$ 的 $\beta-\mathrm{Ni}(\mathrm{OH})_{2}$ 纳米薄片, 然后于 $400^{\circ} \mathrm{C}$ 热处理得到 $\mathrm{NiO}$ 纳 米片. 随后Wang等人 ${ }^{[17]}$ 利用草酸镍和甲胺的水热反 应制备了 $\mathrm{Ni}(\mathrm{OH})_{2}$ 纳米片和多孔的 $\mathrm{NiO}$ 纳米片, 这种独 特的纳米结构具有较大的表面积, 因而作为锂离子 电池的阳极材料, 可以得到比纳米颗粒更优越的电 化学性能. 这两种方法是通过镍盐与氨水或甲胺的 水热反应先得到 $\mathrm{Ni}(\mathrm{OH})_{2}$ 纳米薄片, 然后热处理得到 $\mathrm{NiO}$ 纳米片. 得到的产物为不规则形状纳米片的粉末 状样品. 而有关规则六边形片状结构 $\mathrm{Ni}(\mathrm{OH})_{2}$ 和 $\mathrm{NiO}$
的制备至今未见报道.

目前人们已经研究了氧化镍纳米颗粒的磁学性 质 ${ }^{[23,24]}$, 多孔纳米片 ${ }^{[17]}$ 和海胆结构 ${ }^{[25]}$ 氧化镍的充放 电特性, 而关于具有一定形貌氧化镍纳米结构的光 催化特性至今未见报道. 本文通过金属 $\mathrm{Ni}$ 与草酸钠在 碱性水溶液的水热反应，在金属镍基质的表面原位 生长出直立的形貌规则的六边形 $\mathrm{Ni}(\mathrm{OH})_{2}$ 纳米片, 经 $600^{\circ} \mathrm{C}$ 退火处理得到了直立的六边形 $\mathrm{NiO}$ 纳米片, 研 究了草酸钠在 $\mathrm{Ni}(\mathrm{OH})_{2}$ 纳米片生长过程中的作用, 提 出了可能的生长机理. 我们以甲基橙为光降解染料, 研究了所制备的六边形 $\mathrm{NiO}$ 纳米片的光催化特性.

\section{1 实验}

( i ) $\mathrm{NiO}$ 纳米片的制备. 依次取 $1 \mathrm{~mL}(0.75$ $\mathrm{mol} / \mathrm{L})$ 的草酸溶液和 $1.65 \mathrm{~mL}(1 \mathrm{~mol} / \mathrm{L})$ 的 $\mathrm{NaOH}$ 溶液 于 $50 \mathrm{~mL}$ 烧杯中, 加水 $12.35 \mathrm{~mL}$ 搅拌 $5 \mathrm{~min}$ 后, 将该 混合液移入 $25 \mathrm{~mL}$ 聚四氟乙烯的反应釜中; 金属镍片 $(10 \mathrm{~mm} \times 10 \mathrm{~mm} \times 0.3 \mathrm{~mm})$ 用砂纸抛光, 再用去离子水 和乙醇超声分别洗涤 $15 \mathrm{~min}$, 晾干后将镍片放入上述 反应釜中, 密封, 于 $140^{\circ} \mathrm{C}$ 保温 $24 \mathrm{~h}$, 然后自然冷却至 室温，在金属镍片的表面得到土绿色的薄膜，然后将 该样品以 $1^{\circ} \mathrm{C} / \mathrm{min}$ 的升温速率加热到 $600^{\circ} \mathrm{C}$ 并保温 $2 \mathrm{~h}$ 后, 得到黑色薄膜. 
(ii) 产物的表征. 采用 $\mathrm{X}$ 射线衍射仪(XRD)、 扫描电子显微镜(SEM)和透射电子显微镜(TEM)对产 物的形貌和结构进行了表征. X 射线衍射分析使用的 是日本理学公司的 D/MAX- III C 全自动 X 射线衍射仪, 测试条件为 $\mathrm{CuK \alpha}$ 辐射, 最大管电压 $60 \mathrm{kV}$, 最大管 流 $80 \mathrm{~mA}$, 扫描速度 $8 \% \mathrm{~min}$. 扫描电子显微镜是荷兰 FEI 公司的 Quanta 200 型环境扫描电子显微镜. 透射 电子显微镜使用的是日本电子株式会社的 JEM- 3010 高分辨透射电子显微镜(HRTEM), 加速电压 $200 \mathrm{kV}$. 吸收光谱采用的是北京普析通用仪器有限公司的 TU-1901 型紫外可见分光光度计.

\section{2 结果与讨论}

我们对 $140^{\circ} \mathrm{C}$ 反应 $24 \mathrm{~h}$ 所得的产物进行了 SEM 分析, 结果见图 1. 图 1(a) (c) 为不同放大倍数的 SEM 照片, 从图 1(a)可见, 在镍单质表面有大面积垂直向
上生长的直立的片状纳米结构, 这些纳米片棱角分 明, 呈六边形, 其边长大约在 $0.8 \sim 1.8 \mu \mathrm{m}$, 厚度大约 在 200 500 nm 范围(图 1(b)), 其中有些纳米片相互交 叉生长在一起. 图 1(c)为一完整正六边形纳米片的 SEM 的照片, 其表面光滑, 无明显的缺陷, 相邻边的 夹角为 $120^{\circ}$, 其对角线长大约为 $3.6 \mu \mathrm{m}$. 除了这些较 大尺寸的纳米片外, 我们还发现在镍基质的表面有 一些尺寸较小的纳米片, 这些可能是一些正在生长 的纳米片, 它们继续生长就会长成尺寸较大的完整 的六边形纳米片. 为了确定金属镍表面上纳米片的 微结构, 我们对该样品进行了 TEM 分析, 结果见图 1 (d) (f). 图 1(d)为单个纳米片的 TEM 照片, 从图 1 可 以清楚地看出纳米片近似为六边形结构, 其边的长 度略有差异, 在 800 900 nm 之间, 相邻边的夹角近 似为 $120^{\circ}$, 纳米片的表面比较粗粘. 图 1(e)为相应的 电子衍射图, 图中的衍射斑点呈正六角形排布, 归属
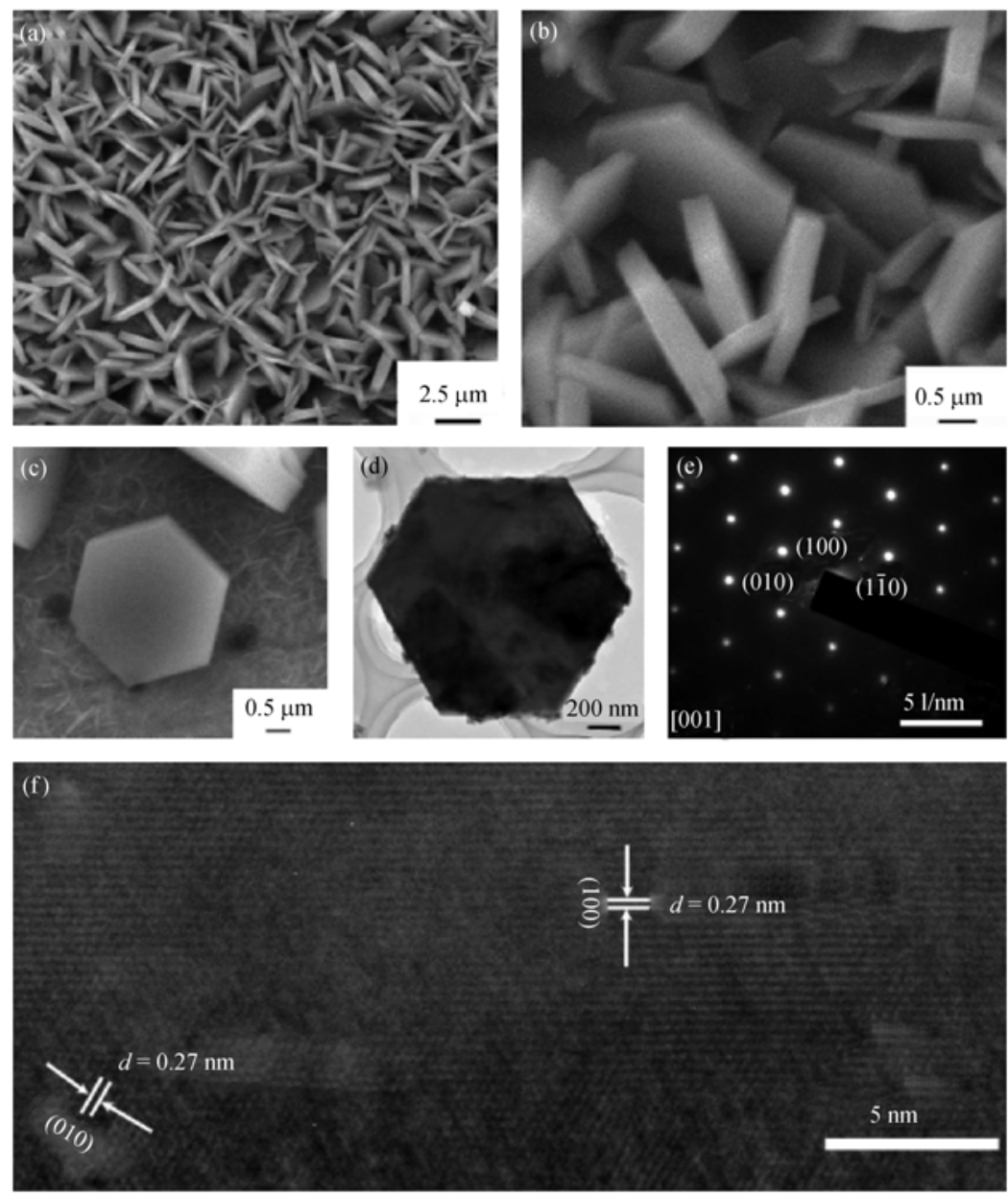

图 1 于 $140^{\circ} \mathrm{C}$ 反应 $24 \mathrm{~h}$ 所得产物的 SEM 和 TEM 照片

(a) (c) 不同放大倍数的 SEM; (d) 单个纳米片的 TEM 照片; (e)、(f) 相应的选区电子衍射照片和高分辨透射电子显微镜照片 
为六方相结构的 [001]晶带轴的衍射, 说明纳米片沿 $\langle 010\rangle$ 方向生长，厚度方向为 [001]. 图 1(f) 为其 HRTEM 照片，图中我们观察到的晶面间距约为 0.27 $\mathrm{nm}$ ，它们对应于六方相 $\mathrm{Ni}(\mathrm{OH})_{2}(100)$ 或(010)面的面 间距. 电子衍射和 HRTEM 说明金属镍表面生长的纳 米片为六方相单晶结构的 $\mathrm{Ni}(\mathrm{OH})_{2}$.

对上述金属镍表面生长的纳米片进行了 XRD 分 析, 结果见图 2. 图 2 中用“*”标注的所有峰的 $2 \theta$ 分 别为 $19.3^{\circ}, 33.1^{\circ}, 38.5^{\circ}, 59.1^{\circ}, 62.7^{\circ}$ 与六方相 $\mathrm{Ni}(\mathrm{OH})_{2}$ (JCPDS No.14-0117, 晶胞参数 $a=0.3123 \mathrm{~nm}, c=$ $0.4620 \mathrm{~nm})$ 的 $(001) 、(100) 、(101) 、(110) 、(111)$ 面的 衍射峰位相对应. 说明金属镍表面生长的纳米片为 六方相 $\mathrm{Ni}(\mathrm{OH})_{2}$. 图中 $2 \theta$ 值为 $44.5^{\circ}, 51.9^{\circ}$ 的衍射峰与 面心立方相镍(JCPDS No.04-0850)的(111)、(200)面的 衍射峰位相对应，此外没有其他杂峰出现，表明通过 该方法在金属镍的表面生长出了纯的六方相 $\mathrm{Ni}(\mathrm{OH})_{2}$ 纳米片。

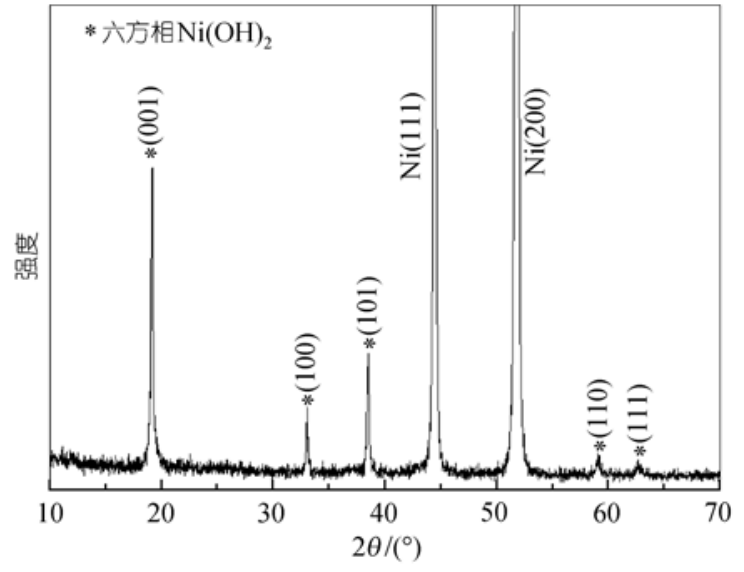

图 2 于 $140^{\circ} \mathrm{C}$ 反应 $24 \mathrm{~h}$ 所得产物的 XRD 图谱

我们将上述制备的样品在 $600^{\circ} \mathrm{C}$ 热处理 $2 \mathrm{~h}$ 以得 到相应结构的 $\mathrm{NiO}$, 对热处理后的样品进行了 SEM 和 TEM 分析. 结果见图 3, 图 3(a) (c)为不同放大倍数 的 SEM 照片, 从图 3 可以观察到退火后产物的形貌
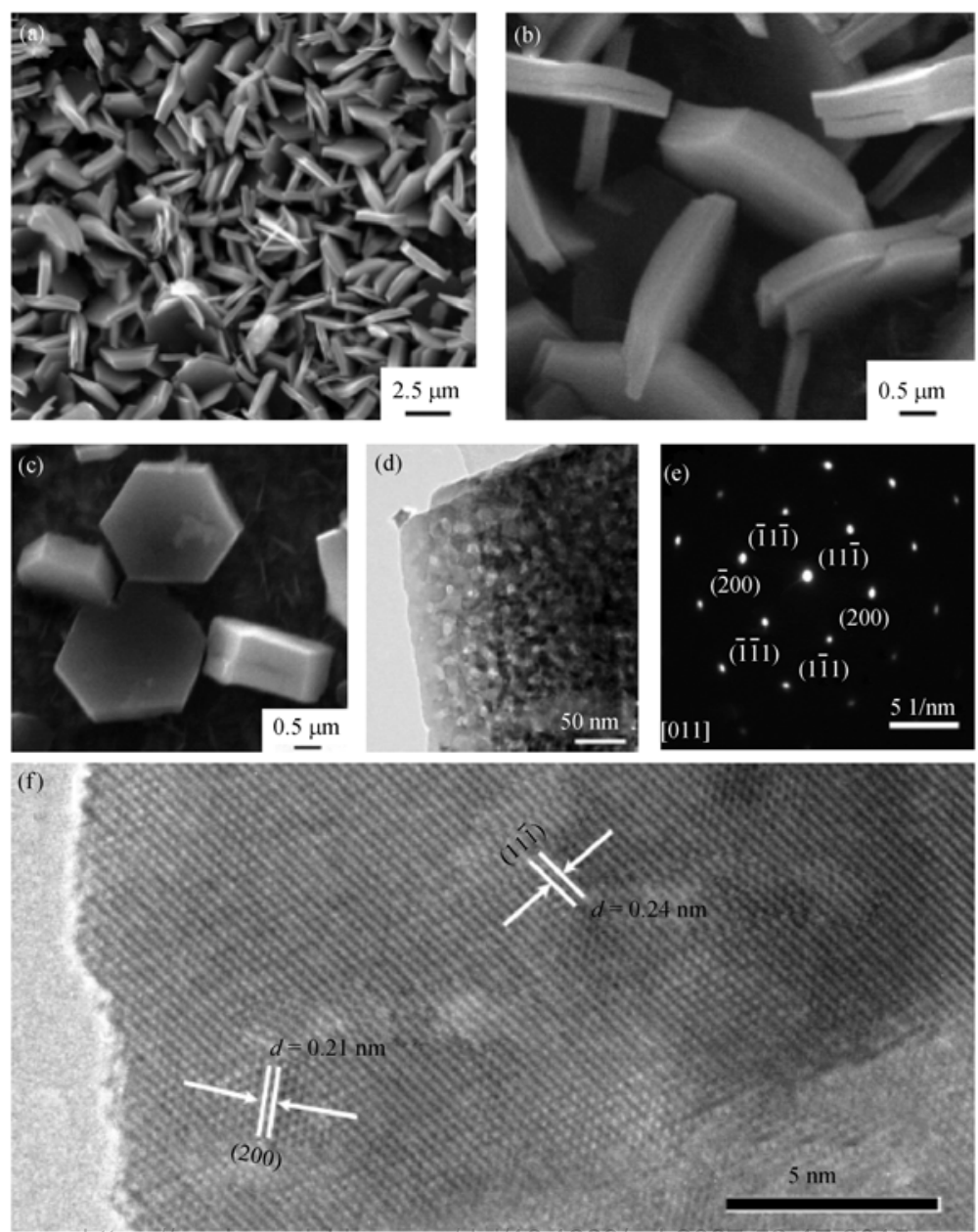

图 3 于 $600^{\circ} \mathrm{C}$ 退火 $2 \mathrm{~h}$ 后得到的纳米片的 SEM 照片(a) (c), TEM 照片(d), 选区电子衍射照片(e)和高分辨 TEM(f) 
仍为垂直向上生长的六边形片状结构(图 3(a)和(b)). 纳米片的对角线长度大约在 $3.5 \mu \mathrm{m}$ 左右, 厚度在 200 500 nm范围, 它们大部分呈层状结构, 有的有明 显的裂纹(图3(b)). 从图3(c)我们观察到完整的六边形 的纳米片, 其形貌近似为正六边形, 边长约为 $0.8 \sim 1.7 \mu \mathrm{m}$, 厚度约为 500 900 nm范围. 在尺寸较大 的纳米片的底部镍基质上有尺寸较小的纳米片. 这 些结果与图 1(a) (c)的SEM相对应. 热处理后唯一不 同之处就是大部分纳米片明显成层状结构, 有的有 明显的裂缝, 这可能是由于 $\mathrm{Ni}(\mathrm{OH})_{2}$ 为层状结构的缘故. 我们知道六方结构的 $\mathrm{Ni}(\mathrm{OH})_{2}$ 为层状结构, 层间距离 $4.608 \mathrm{~nm}$, 其晶体结构的模型见图 $4^{[26]}$. 高温脱水时 层间每两个 $\mathrm{OH}$ 脱去一个 $\mathrm{H}_{2} \mathrm{O}$ 分子形成 $\mathrm{NiO}$, 形成 $\mathrm{NiO}$ 后层间距离减小, 这样就会在原层状结构中产生间 隙，随着反应的进行，纳米片中层间隙就会增加，达 到一定程度就会发生断裂, 形成裂缝, 从而得到层状 结构 $\mathrm{NiO}$. 图 3(d)为 $\mathrm{NiO}$ 纳米片一个角的 TEM照片, 从图可看到纳米片表面不光滑, 有很多直径约 $15 \mathrm{~nm}$ 左右的凹坑, 这可能由于退火过程 $\mathrm{Ni}(\mathrm{OH})_{2}$ 脱水, 原 结构中原子数量减少, 纳米片中产出空隙, 随着反应 的进行, 空隙就增加, 从而形成凹坑. 图3(e)为 $\mathrm{NiO}$ 纳 米片的电子衍射照片, 其衍射图归属为单晶结构立 方相 $\mathrm{NiO}[011]$ 晶带轴的衍射图. 图 3(f) 为相应的 HRTEM照片, 从图测量的晶面间距为 0.21 和 $0.24 \mathrm{~nm}$, 它们分别与立方相 NiO的(111)和(200)面的面间距一 致. 电子衍射和HRTEM说明热处理后的纳米片为立 方相单晶结构的 $\mathrm{NiO}$.

对上述热处理的产物进行了 XRD 分析, 结果如 图 5 所示. 图 5 中用“*”标注的衍射峰的 $2 \theta$ 值分别为 $37.2^{\circ}, 43.3^{\circ}, 62.8^{\circ}$ 与立方相 $\mathrm{NiO}$ (JCPDS 卡 No. 47-

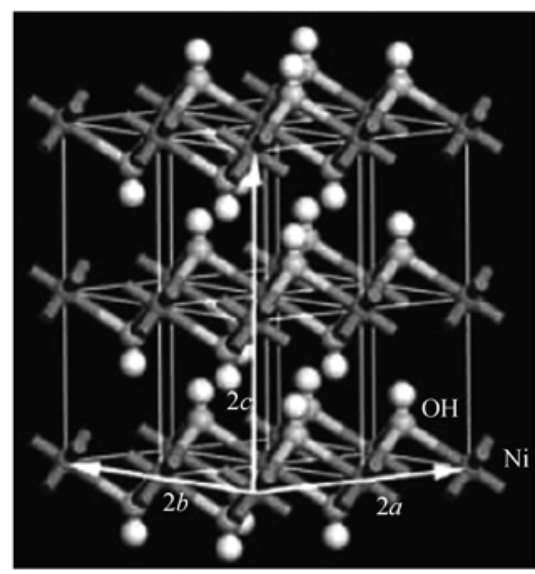

图 $4 \beta-\mathrm{Ni}(\mathrm{OH})_{2}$ 晶体结构的根球模型 $(2 \times 2 \times 2$ 单胞 $)$

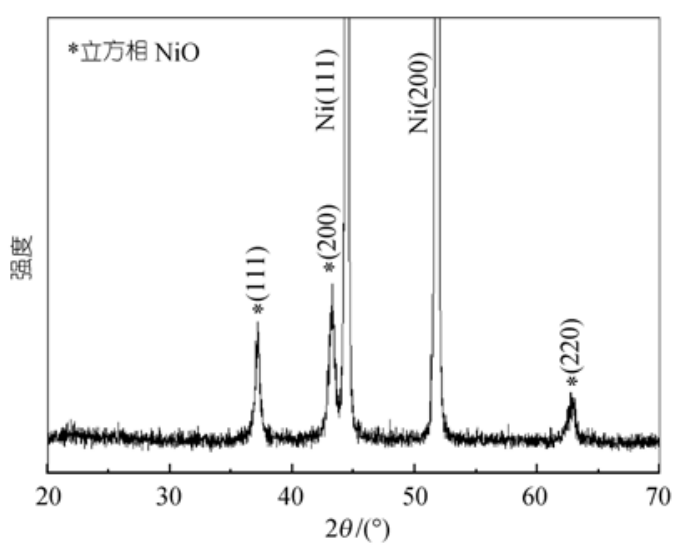

图 $5 \mathrm{NiO}$ 纳米片的 XRD 图谱

1049)的(111)、(200)、(220)面的衍射峰位相对应，并 且没有观察到六方相 $\mathrm{Ni}(\mathrm{OH})_{2}$ 的峰, 表明产物已完全 转化为立方相 $\mathrm{NiO}$. 图中 $2 \theta$ 值分别为 $44.5^{\circ}, 51.9^{\circ}$ 的 衍射峰为金属镍基质的(111)、(200)面的衍射峰.

以上研究表明, 镍片与草酸钠的碱性水溶液在 $140^{\circ} \mathrm{C}$ 反应 $24 \mathrm{~h}$ 后, 在镍基质表面生长出六边形单晶 结构的 $\mathrm{Ni}(\mathrm{OH})_{2}$ 纳米片, 经过 $600^{\circ} \mathrm{C}$ 热处理得到相应 结构的 $\mathrm{NiO}$ 纳米片. 为了说明草酸在 $\mathrm{Ni}(\mathrm{OH})_{2}$ 纳米片 形成过程中的作用, 我们不加草酸, 让镍片与 $\mathrm{NaOH}$ 水溶液于 $140^{\circ} \mathrm{C}$ 水热反应 $24 \mathrm{~h}$, 得到的产物进行了 SEM 和 XRD 分析, 结果见图 6(a)和(b). 从图 6(a)的 SEM 照片, 我们没有观察到六边形片状结构. 在图 6(b)的 XRD 图谱中我们只发现了面心立方相单质镍 的衍射峰, 没有观察到 $\mathrm{Ni}(\mathrm{OH})_{2}$ 的衍射峰, 表明单质 镍与 $\mathrm{NaOH}$ 溶液在 $140^{\circ} \mathrm{C}$ 不能生成 $\mathrm{Ni}(\mathrm{OH})_{2}$, 而在该 体系加入草酸后, 则在单质镍片上形成了六边形的 $\mathrm{Ni}(\mathrm{OH})_{2}$ 纳米片, 说明草酸在 $\mathrm{Ni}(\mathrm{OH})_{2}$ 纳米片的形成 过程中起着非常重要的作用. 在 $\mathrm{Ni}-\mathrm{H}_{2} \mathrm{C}_{2} \mathrm{O}_{4}-\mathrm{NaOH}$ 水 热体系中可能的化学反应为: 镍片首先与反应金中少 量的氧气和草酸钠反应得到配离子, 配离子电离产生 $\mathrm{Ni}^{2+}, \mathrm{Ni}^{2+}$ 与溶液中 $\mathrm{OH}^{-}$反应生成 $\mathrm{Ni}(\mathrm{OH})_{2}, \mathrm{Ni}(\mathrm{OH})_{2}$ 高 温脱水得到 $\mathrm{NiO}$ 纳米晶. 其反应方程式如下:

$$
\begin{aligned}
2 \mathrm{Ni}+4 \mathrm{C}_{2} \mathrm{O}_{4}{ }^{2-}+2 \mathrm{H}_{2} \mathrm{O}+\mathrm{O}_{2} & \rightleftharpoons 2\left[\mathrm{Ni}\left(\mathrm{C}_{2} \mathrm{O}_{4}\right)_{2}\right]^{2-}+4 \mathrm{OH}^{-} \\
{\left[\mathrm{Ni}\left(\mathrm{C}_{2} \mathrm{O}_{4}\right)_{2}\right]^{2-} } & \rightleftharpoons \mathrm{Ni}^{2+}+2 \mathrm{C}_{2} \mathrm{O}_{4}{ }^{2-} \\
\mathrm{Ni}^{2+}+2 \mathrm{OH}^{-} & \rightleftharpoons \mathrm{Ni}(\mathrm{OH})_{2} \\
\mathrm{Ni}(\mathrm{OH})_{2} & \stackrel{\text { 退火 }}{\longrightarrow} \mathrm{NiO}+\mathrm{H}_{2} \mathrm{O}
\end{aligned}
$$

在上述反应过程中, 由于反应 (3)的发生, 使平 衡(1)(2)向右移动, 以维持反应(3)的继续进行, 最终 在镍片表面生长出了六边形结构的 $\mathrm{Ni}(\mathrm{OH})_{2}$ 纳米片. 在 $\mathrm{Ni}(\mathrm{OH})_{2}$ 纳米片的生长过程中 $\mathrm{C}_{2} \mathrm{O}_{4}{ }^{2-}$ 起了很重要的 

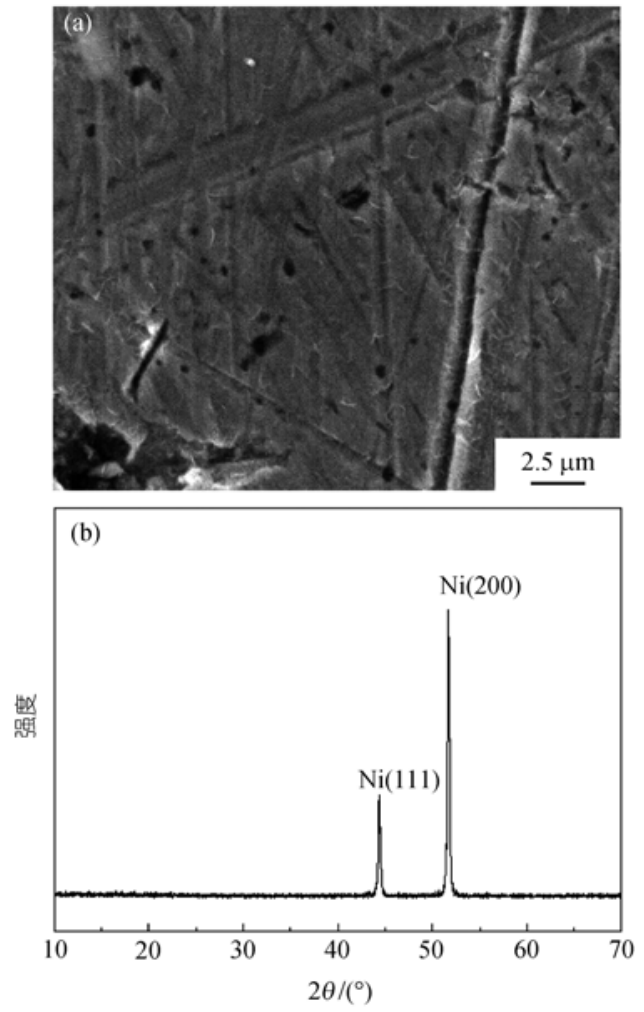

图 6 不加草酸镍片与 $\mathrm{NaOH}$ 溶液反应制备的样品的 SEM 图(a)和 XRD 图(b)

作用, 它通过与Ni配位形成 $\left[\mathrm{Ni}\left(\mathrm{C}_{2} \mathrm{O}_{4}\right)_{2}\right]^{2-}$, 降低了 $\mathrm{Ni}$ 的 电极电位, 促进单质 $\mathrm{Ni}$ 的氧化, 又通过反应(2)控制 溶液中 $\mathrm{Ni}^{2+}$ 的浓度, 以控制 $\mathrm{Ni}(\mathrm{OH})_{2}$ 纳米片的生长. 晶体的形状主要取决于晶核的形成与生长过程中不 同方向上的生长速度. 六方结构的 $\mathrm{Ni}(\mathrm{OH})_{2}$ 为层状结 构(图 4). 其中 $\mathrm{Ni}(\mathrm{OH})_{2}$ 分子在垂直于 $z$ 轴的 $x y$ 平面上, 镍、氧原子呈层状分布, 层内每个 $\mathrm{Ni}$ 与 6 个氧原子配 位, 其中 3 个氧原子在面的上方, 另 3 个氧原子在面的 下方. 层间距离 $4.608 \mathrm{~nm}$, 氢原子单独形成一层“氢 层”, 氢原子距最近层距离大约 $1.1 \mathrm{~nm}$, 这样在一定的 水热条件下, 通常沿 $x y$ 平面生长形成 $\mathrm{Ni}(\mathrm{OH})_{2}$ 纳米片, 纳米片的厚度方向为 $[001]$ 方向 (即 $z$ 轴方向 $)^{[24]}$. 在我 们的水热体系中通过反应 $(1)$ 和 $(2)$ 控制 $\mathrm{Ni}(\mathrm{OH})_{2}$ 纳米晶 的生长, 使其沿 $\langle 010\rangle( \pm[0 \overline{1} 0], \pm[100], \pm[1 \overline{1} 0])$ 的 6 个 方向几乎等速生长得到正六边形的六方结构的 $\mathrm{Ni}(\mathrm{OH})_{2}$ 纳米片, 经 $600^{\circ} \mathrm{C}$ 热处理脱水得到立方相单 晶结构 $\mathrm{NiO}$ 纳米片.

我们以甲基橙为光降解染料, 研究了所制备的 六边形 $\mathrm{NiO}$ 纳米片的光催化特性. 将 $0.0163 \mathrm{~g}$ 甲基 橙用水溶解, 溶解后转移到 $1000 \mathrm{~mL}$ 容量瓶中, 然后
用水稀释至刻度得到 $5.0 \times 10^{-5} \mathrm{~mol} / \mathrm{L}$ 甲基橙溶液. 取 3 份 $15 \mathrm{~mL} 5.0 \times 10^{-5} \mathrm{~mol} / \mathrm{L}$ 甲基橙溶液, 其中一份放入 金属Ni 片(0.329 g)，另一份放入表面生长有六边形氧 化镍纳米片的 $\mathrm{Ni}$ 金属片 $(0.346 \mathrm{~g}), 3$ 份溶液在日光下 照射 $5 \mathrm{~h}$ 后测试其吸收光谱, 结果见图 7. 从图 7 可 见, 有镍片和表面生长有六边形 $\mathrm{NiO}$ 纳米片的镍单 质的溶液吸收峰与甲基橙溶液相比略有降低, 其中 表面生长有六边形 $\mathrm{NiO}$ 纳米片镍单质的溶液的吸收峰 降低较为明显. 甲基橙吸收峰的降低是由于被空气 氧化降解的缘故. 说明金属 $\mathrm{Ni}$ 和六边形氧化镍纳米 片对空气氧化降解甲基橙有一定的催化作用, 其中 六边形氧化镍纳米片的催化作用相对较大. 此外, 我 们又研究了双氧水对甲基橙氧化降解的作用，同样 我们取 3 份甲基橙溶液, 分别加入 5 滴 $30 \% \mathrm{H}_{2} \mathrm{O}_{2}$, 然 后按上述方法进行实验, 测得的吸收光谱见图 8.

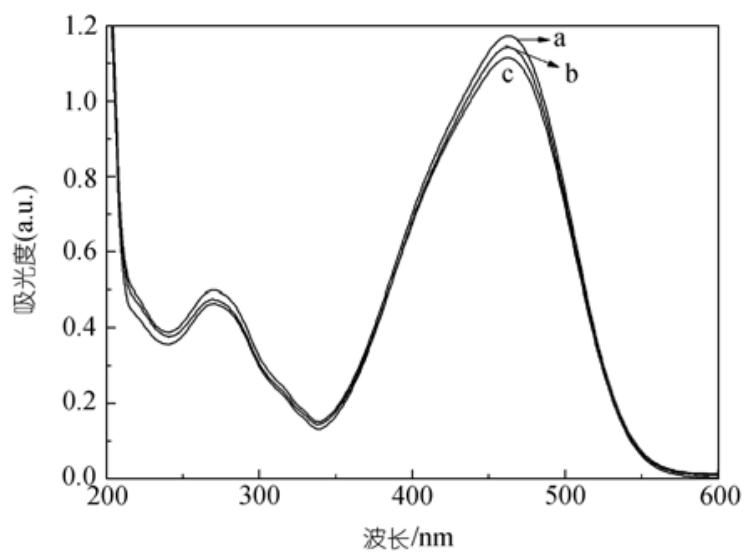

图 7 不同溶液光照 $5 \mathrm{~h}$ 后的紫外可见吸收谱 (a) 甲基橙溶液; (b) 含有单质镍的甲基橙溶液; (c) 含有 $\mathrm{NiO}$ 纳米片的甲基橙溶液

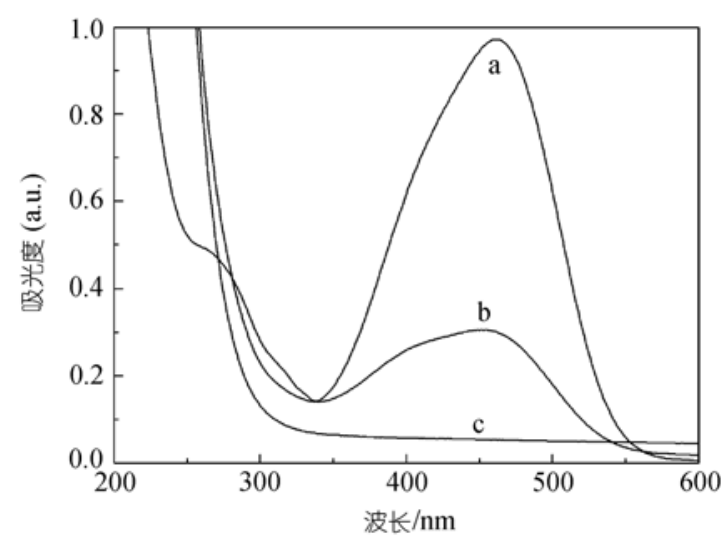

图 8 不同溶液光照 $5 \mathrm{~h}$ 后的紫外可见吸收谱 (a) $\mathrm{H}_{2} \mathrm{O}_{2}$-甲基橙溶液; (b) 含有单质镍的 $\mathrm{H}_{2} \mathrm{O}_{2}$-甲基橙溶液; (c) 含有 $\mathrm{NiO}$ 纳米片的 $\mathrm{H}_{2} \mathrm{O}_{2}$-甲基橙溶液 
从图 8 我们发现, 含有镍片的溶液中甲基橙的吸 收峰明显降低, 含有表面生长有六边形 $\mathrm{NiO}$ 纳米片的 镍单质的溶液中甲基橙的吸收峰完全消失，甲基橙 吸收峰的降低和消失是由于它被双氧水氧化而降解. 这说明镍单质和表面生长有六边形氧化镍纳米片对 双氧水氧化降解甲基橙具有一定的光催化作用, 其 中六边形氧化镍纳米片的光催化作用最大.

\section{3 结论}

通过镍片在草酸钠的碱性溶液中的水热反应大 规模制备了六边形结构的 $\mathrm{Ni}(\mathrm{OH})_{2}$ 纳米片, 经过热处 理得到六边形 $\mathrm{NiO}$ 纳米片. 该方法不同于已报道的镍 盐与氨水或甲胺的水热反应, 它通过金属单质与相 应的配位剂的水热反应在金属单质表面原位生长出 氢氧化物纳米结构, 然后热处理得到相应纳米结构 的 $\mathrm{NiO}$. 在 $\mathrm{Ni}(\mathrm{OH})_{2}$ 纳米片的生长过程中 $\mathrm{C}_{2} \mathrm{O}_{4}{ }^{2-}$ 起了 很重要的作用, 由于与镍的配位作用降低了镍的电 极电位, 促进了镍单质的氧化, 同时又控制着 $\mathrm{Ni}(\mathrm{OH})_{2}$ 的成核和生长, 以制备六边形的片状结构. 该方法操作简便, 反应条件温和, 可用于大规模的工 业生产. 研究了所制备的六边形 $\mathrm{NiO}$ 纳米片的光催化 特性. 结果发现, 在光照射下它对空气和双氧水氧化 降解甲基橙具有一定的催化作用. 此外, 我们通过这 种金属-配合剂水热法制备了 $\mathrm{ZnO}$ 纳米棒阵列, 纳米 锥阵列和 $\mathrm{Fe}_{3} \mathrm{O}_{4}$ 纳米片等氧化物纳米结构. 说明该方 法是一种制备氧化物纳米结构的通用方法. 相关的 研究正在进行中.

致谢 感谢陕西师范大学化学与材料科学学院的王林芳老 师在 SEM 测试方面提供的帮助.

\section{参考文献}

1 Liang Z H, Zhu Y J, Hu X L. $\beta$-nickel hydroxide nanosheets and their thermal decomposition to nickel oxide nanosheets. J Phys Chem B, 2004, 108(11): 3488-3491[DOI]

2 Wu L L, Wu Y S, Wei H Y, et al. Synthesis and characteristics of $\mathrm{NiO}$ nanowire by a solution method. Mater Lett, 2004, 58(21): 2700-2703[DOI]

3 丁维平, 杨晓萍, 王光明. 电沉积-烧结制备掺杂 $\mathrm{C}, \mathrm{Co}$ 的纳米 $\mathrm{NiO}$ 电极及其电容性能. 科学通报, 2004, 49(11): 1052-1055

4 Park J, Kang E, Son S U, et al. Monodisperse nanoparticles of Ni and $\mathrm{NiO}$ : Synthesis, characterization, self-assembled superlattices, and catalytic applications in the suzuki coupling reaction. Adv Mater, 2005, 17(4): 429-434 [DOI]

5 Han D Y, Yang H Y, Shen C B, et al. Synthesis and size control of $\mathrm{NiO}$ nanoparticles by water-in-oil microemulsion. Powder Technol, 2004, 147(1-3): 113-116[DOI]

6 Dharmaraj N, Prabu P, Nagarajan S, et al. Synthesis of nickel oxide nanoparticles using nickel acetate and poly(vinylacetate) precursor. Mater Sci Eng B, 2006, 128(1-3): 111-114[DOI]
7 Li X L, Zhang X X, Li Z R, et al. Synthesis and characteristics of $\mathrm{NiO}$ nanoparticles by thermal decomposition of nickel dimethylglyoximate rods. Solid State Commun, 2006, 137(11): 581584[DOI]

8 Wang Y G, Xia Y Y. Electrochemical capacitance characterization of $\mathrm{NiO}$ with ordered mesoporous structure synthesized by template SBA-15. Electrochim Acta, 2006, 51(16): 3223-3227 [DOI]

9 Lin Y, Xie T, Cheng B C, et al. Ordered nickel oxide nanowire arrays and their optical absorption properties. Chem Phys Lett, 2003, 380(5-6): 521-525[DOI]

$10 \mathrm{Xu} \mathrm{C} \mathrm{K}$, Hong $\mathrm{K} \mathrm{Q}$, Liu S, et al. A novel wet chemical route to NiO nanowires. J Cryst Growth, 2003, 255(3-4): 308-312[DOI]

11 Needham S A, Wang G X, Liu H K. Synthesis of NiO nanotubes for use as negative electrodes in lithium ion batteries. J Power Sources, 2006, 159(1): 254-257[DOI]

12 Wang W Z, Liu Y K, Xu C K, et al. Synthesis of NiO nanorods by a novel simple precursor thermal decomposition approach. Chem Phys Lett, 2002, 362(1-2): 119-122 [DOI]

13 Matsui K, Pradhan Bhabendra K, Kyotani T, et al. Formation of nickel oxide nanoribbons in the cavity of carbon nanotubes. J Phys Chem B, 2001, 105(24): 5682-5688 [DOI]

14 Ni X M, Zhao Q B, Zhou F, et al. Synthesis and characterization of NiO strips from a single source. J Cryst Growth, 2006, 289(1): 299-302 [DOI]

15 Liu X H, Qiu G Z, Wang Z, et al. Rationally synthetic strategy: From nickel hydroxide nanosheets to nickel oxide nanorolls. Nanotech, 2005, 16: 1400-1405 [DOI]

16 Liang J H, Li Y D. Synthesis and characterization of $\mathrm{Ni}(\mathrm{OH})_{2}$ single nanorods. Chem Lett, 2003, 32(12): 1126-1127 [DOI]

17 Wang X, Li L, Zhang Y G, et al. High-yield synthesis of $\mathrm{NiO}$ nanoplatelets and their excellent electrochemical performance. Cryst Growth Des, 2006, 6(9): 2163-2165 [DOI]

18 Sun X M, Liu J F, Li Y D. Use of carbonaceous polysaccharide microspheres as templates for fabricating metal oxide hollow spheres. Chem Eur J, 2006, 12(7): 2039-2047 [DOI]

19 Titirici M M, Antonietti M, Thomas A. A generalized synthesis of metal oxide hollow spheres using a hydrothermal approach. Chem Mater, 2006, 18(16): 3808-3812 [DOI]

20 Wang D B, Song C X, Hu Z S, et al. Fabrication of hollow spheres and thin films of nickel hydroxide and nickel oxide with hierarchical structures. J Phys Chem B, 2005, 109(3): 1125-1129[DOI]

21 Wang Y, Zhu Q S, Zhang H G. Fabrication of $\beta-\mathrm{Ni}(\mathrm{OH})_{2}$ and $\mathrm{NiO}$ hollow spheres by a facile templatefree process. Chem Commun, 2005, 5231-5233

22 Liu J, Du S F, Wei L Q, et al. Template-free synthesis of NiO hollow microspheres covered with nanoflakes. Mater Lett, 2006, 60(29-30): 3601-3604[DOI]

23 Parada C, Moran E. Microwave-assisted synthesis and magnetic study of nanosized Ni/NiO materials. Chem Mater, 2006, 18(11): $2719-2725[\mathrm{DOI}]$

24 Ichiyanagi Y, Wakabayashi N, Yamazaki J, et al. Magnetic properties of NiO nanoparticles. Physica B, 2003, 329-333: 862863 [DOI]

25 Liu X M, Zhang X G, Fu S Y. Preparation of urchinlike NiO nanostructures and their electrochemical capacitive behaviors. Mater Res Bull, 2006, 41(3): 620-627[DOI]

26 王文帝, 刘金华, 王大志, 等. $\mathrm{Ni}(\mathrm{OH})_{2}$ 纳米晶的水热合成和结 构表征. 过程工程学报, 2006, 6(1): 128一131 